\title{
Adherence and scratching resistance of nanometric titania films
}

\author{
Suzy Pascoali ${ }^{1}$, Lucas Dominguini ${ }^{2,}$, , Joel Brasil Borges ${ }^{1}$, Orestes Estevam Alarcon ${ }^{3}$ \\ ${ }^{1}$ Federal Institute of Santa Catarina, Araranguá, Brazil \\ ${ }^{2}$ Federal Institute of Santa Catarina, Criciúma, Brazil \\ ${ }^{3}$ Federal University of Santa Catarina, Florianópolis, Brazil
}

\section{Email address:}

suzy.pascoali@ifsc.edu.br (S. Pascoali), lucas.dominguini@ifsc.edu.br (L. Dominguini)

To cite this article:

Suzy Pascoali, Lucas Dominguini, Joel Brasil Borges, Orestes Estevam Alarcon. Adherence and Scratching Resistance of Nanometric Titania Films. Advances in Materials. Vol. 3, No. 1, 2013, pp. 1-5. doi: 10.11648/j.am.20140301.11

\begin{abstract}
TiO}_{2}$ films has been used to extend the wear resistance in bearing, seals for pumps and bone prostheses. In this study was analyzed the conventional hardness and scratch toughness. The scratching test equipment used was developed at the Laboratory of materials Labmat / UFSC. The tests were performed on Titania films deposited on glass plates and ceramics via reactive DC magnetron sputtering. The films were deposited by 10, 15 and $60 \mathrm{~min}$. One of the samples has a titanium metal film of a few nanometers thick between the substrate and the Titania film, the oxide has been deposited for 30 min. At this rang of tests loads the deposited films show good adhesion to substrate, there was no cracking or spelling of the film.
\end{abstract}

Keywords: Titania Nanometrics Films, Scratching Resistance, Magnetron Sputtering DC

\section{Introduction}

Tribological characteristics of recover surfaces by thin films influences its function, life on service and productivity. A technique used for character tribological resistant films is scratching tests. In order to standardize the results is developing standard tests for performance on calibration and monitoring of the devices that make scratching tests [1]. Results are analyzed after the sample was scratched with a diamond indenter Rockwell C, radius $200 \pm 10 \mu \mathrm{m}$. Tests were monitored the critical loads $\mathrm{Lc}_{1}, \mathrm{Lc}_{2} \mathrm{e} \mathrm{Lc}_{3}$. For purposes of standardization has been determined that the critical loads are taken, when the onset of new types of cracks. Load limit one $\left(\operatorname{Lc}_{1}\right)$ on loads that begins the appearance of cracks on the edges of the scratch V. Load limit two $\left(\mathrm{Lc}_{2}\right)$ on loads which starts chipping at the interface film/substrate, together with the cracks in V. Load limit three $\left(\mathrm{Lc}_{3}\right)$ on strength that appear coarse chips, so called conchoidal cracks. The failing formed may be different depending on the film and substrate material. Material scratch resistance is influenced by film hardness and thickness, the cohesive and adhesion strength between film and substrate, speed scratch, rate load, beside outside factors, such as indenter radius and hardness substrate material.

The critical load increases with the radius of indenter due to the load distribution on a larger area and thus reduce pressure zone under the indenter and elastic-plastic proper-ties of the material of the film [2].

Critical load (Lc) The critical load (Lc) is considered de-pendent indenter radius ( $R$ ) but for the purpose of modeling was removed correlation with the scratch depth $\delta \mathrm{Cr}$ and the critical hardness of the composite film substrate (Hcr) [3]. In this case, for track condition elastic-plastic adhesive and the dependence of the critical load has been represented as:

$$
\mathrm{L}_{\mathrm{c}}=2 \pi \mathrm{R} \gamma \delta_{\mathrm{cr}} \mathrm{H}_{\mathrm{cr}}
$$

Which $\gamma$ is a dimensionless parameter. The scratch hardness is proportional to the applied load and inversely proportional to width scratch. Can be obtained as:

$$
\mathrm{H}_{\mathrm{r}}=\frac{\mathrm{L}}{2 \pi \mathrm{R} \delta}
$$

Ishimura and Rodrigo state that the hardness of the scratch can be determined as a function of material hardness through the constant $\gamma=\mathrm{H}_{\mathrm{f}}=\gamma \mathrm{H}_{\mathrm{Cr}}$ and $\lambda$ experimentally obtained values around 0,7 when used indenter radius of 200 microns.

The hardness of the composite film substrate was achieved using the following equation: 


$$
H_{c}=3\left(\frac{t}{d}\right)\left(\frac{H_{f}}{H_{s}}\right)^{1 / n}\left(H_{f}-H_{s}\right) \tan ^{1 / 3} \theta+H_{s}
$$

where $\mathrm{t}$ is film thickness, $\mathrm{d}$ is indentation diagonal, is the half angle of the indenter opposite face, $\mathrm{n}$ is related to materials properties, was determined as 2 in TiN films evaporated, and 3 in $\mathrm{CrN}$ film evaporated by arc on metallic substrates.

The film hardness was given by the indenter size as:

$$
\begin{aligned}
& \mathrm{H}_{\mathrm{TiN}}=38,5 \mathrm{~d}^{-0,25} \\
& \mathrm{H}_{\mathrm{CrN}}=28,1 \mathrm{~d}^{-0,16}
\end{aligned}
$$

The scratch depth increases with the diameter of indenter and was independent of the base material, yet has not changed $\lambda$. Ishimura characterizes this constancy of $=0.7$ as a predominance of the effect of plastic on elastic deformation in indenter and scratching.

If was considered an elastoplastic initial deformation, the variation of the critical load with the radius is not linear, since it influences the scratch hardness and depth. Being the critical load equation in the form:

$$
\mathrm{L}_{\mathrm{c}}=2 \pi \mathrm{R}^{\mathrm{m}} \gamma \delta_{\mathrm{cr}} \mathrm{H}_{\mathrm{cr}}
$$

with the exponent "m" oscillating close to 1 with values between 0.85 and 1.3 .

For some manufacturing processes such as spray coating is necessary to control film fracture toughness. Fevel shows a method for measuring film toughness by microhardness tests. The hardness was measured by applying a indenter Vickers on load (P) using $300 \mathrm{~g}$ weight for 15 seconds. Value of fracture toughness was estimated by measuring the crack length (c) after a indentation of $3 \mathrm{~kg}$ for $30 \mathrm{~s}$. After obtaining the average of 20 measured in the cross section of the sample formulas used were:

$$
K=0,016 \frac{P}{\sqrt{c^{\sqrt{3}}}} \sqrt{\frac{E}{P}} \quad K=0,273 \frac{a}{c} \sqrt{\frac{P E}{c}}
$$

where $\mathrm{a}$ is the diagonal indentation Vickers, H Vickers hardness and E the Young's modulus estimated at 100GPa for all films [4].

\section{Aspects of Tribological films $\mathrm{TiO}_{2}$}

$\mathrm{TiO}_{2}$ films have been used to increase the wear resistance in bearings, in light bearing, sleeves flat seals in pumps and bone prostheses [5]. However, there is little knowledge available on the tribological properties of Titania thin films.

Anatase films deposited by sol-gel have been characterized and studied the mechanisms of wear. The formed film has wear at low loads $(<3 \mathrm{~N})$ appearance of microscratching, was observed plastic deformation and microcracks, and small particles adhered to film, and the occurrence of abrasion wear [6].

In another study, we analyzed amorphous $\mathrm{TiO}_{2}$ films deposited on glass obtained by magnetron sputtering DC ( Ra $=15 \mathrm{~nm}, \mathrm{H}=10,9 \mathrm{GPa}, \mathrm{Lc}=7 \mathrm{~N}, \mu=0,2=>0,8)$ and pulsed $(\mathrm{Ra}=3 \mathrm{~nm}, \mathrm{H}=12,6 \mathrm{GPa}, \mathrm{Lc}=22 \mathrm{~N}, \mu=0,2=>0,6)$ [7].

The friction and wear coefficient of $\mathrm{TiO}_{2}$ film are affected by the presence of fluids such as water and ethanol. The fol-lowing figure shows a plot of friction obtained by the applied load, the measured torque and the radius of the ring block in a test-drive, block Titania $(\mathrm{Ra}<0.1 \mathrm{~mm})$ and disc $\mathrm{Cr}_{3} \mathrm{C}_{2}-\mathrm{NiCr}(\mathrm{Ra}=0,6 \mu \mathrm{m})$. The applied load was $800 \mathrm{~N}$ to $0.42 \mathrm{~m} / \mathrm{s}$ and the contact width of $6 \mathrm{~mm}$. Friction and wear are greatest for the lubricated system to the dry water. Ethanol reduced friction and wear of $\mathrm{Cr}_{3} \mathrm{C}_{2}-\mathrm{NiCr}$, but increased wear of $\mathrm{TiO}_{2}$. The Titania surface worn in water showed pitting and plastic fatigue, microcracks, with chipping and fracture scratch. The worn surface of $\mathrm{TiO}_{2}$ in ethanol showed a greater number of microcracks, however, less crack size.

The absorption of polar molecules such as water and ethanol enhances corrosion cracking. The surfaces of these films have been deposited by spray outer pores and cracks. Putting these two facts to the presence of polar molecules induced stress corrosion cracking, chipping and had propagated microcracks and fracture, resulting in greater wear than in dry slid-ing. Ethanol may have cooled better contact.

\section{Experimental}

Tests were performed on $\mathrm{TiO}_{2}$ films deposited on glass and ceramics plates via reactive magnetron sputtering DC. Four glass samples. Films were deposited by 10,15 and 60 min. One of the samples has a titanium metal film of a few nanometers thick between the substrate and the Titania, the oxide has been deposited for $30 \mathrm{~min}$.

The thickness of the films was measured by its cross section by SEM. The morphology of the film was obtained with an $\mathrm{X}$-ray diffractometer (Kint 200) $\mathrm{Cu}-\mathrm{k} \alpha$. To make analysis of the film was primarily used a incident angle of $0,5^{\circ}$.

Microhardness was measured with a Shimadzu Vickers indenter. The load was applied for $15 \mathrm{~s}$. Strength used were $0.0987 \mathrm{~N}, 0.2452 \mathrm{~N}, \mathrm{~N} 0.4903,0.9807 \mathrm{~N}, 1.961 \mathrm{~N}$ and 2.942 $\mathrm{N}$. Due to the thin film, the same could not be measured hardness across.

The scratch test used was developed at the Laboratory of materials Labmat / UFSC. The indenter was tool steel sphere of radius $2.5 \mathrm{~mm}$ with error of sphericity of 5 microns. Test was performed using scratching speed of $1 \mathrm{~mm} / \mathrm{s}$ initial strength of $0.5 \mathrm{~N}$ to $0.5 \mathrm{~N}$ implement load / s to $3 \mathrm{~N}$. Tests were conducted with constant load of $0,5 \mathrm{~N}$ and a speed of 1 $\mathrm{mm} / \mathrm{s}$. There were three scratch in each sample with the critical load being determined by the presence of cracks along it. The width was measured in electron microscope.

\section{Results and Discussion}

Thickness of these films were measured using the SEM pictures of filmcross section. Deposited film has a thickness of $30 \mathrm{~min} 820 \mathrm{~nm}$. The X-ray diffractogram is following. 


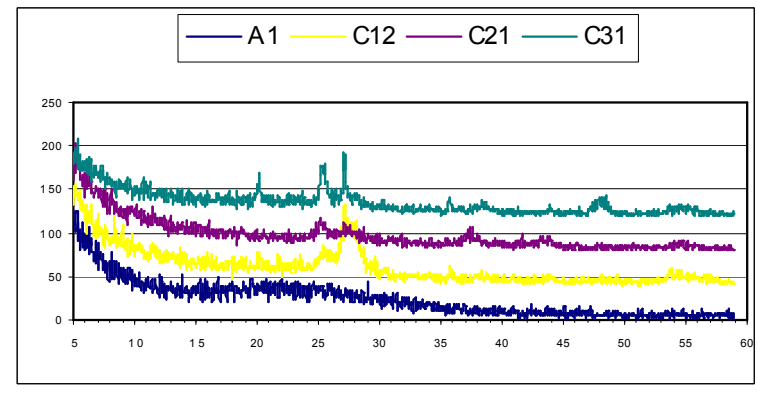

Figure 1. X-ray diffractogram upwards deposited on ceramic films 10, 15, 30 and $60 \mathrm{~min}$.

The XRD patterns presented confirm films are deposited on titanium dioxide. However, the XRD peak did not show any structure in film obtained in test 1 , which suggests that it should be very thin or amorphous. It can show a repeating pattern of two forms of diffraction peaks. A first set of $2 \theta 25$, 35,48 and $55^{\circ}$ corresponds with anatase, the second set $2 \theta$ $27,38,44$ and $53^{\circ}$ corresponds rutile diffractogram. Second test sample diffractogram corresponding to rutile and other two tests has an intensity distribution similar peaks in diffractogram of both anatase and rutile. The hardness with the film and substrate are in Figure 2 e 3.

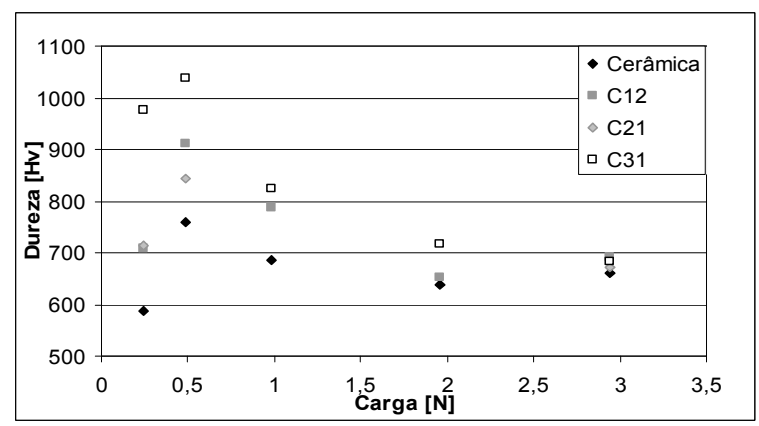

Figure 2. Hardness TiO2 film deposited on ceramic via magnetron sputtering (for $15 \mathrm{~min} \mathrm{C12,C21} \mathrm{and} \mathrm{C31} \mathrm{for} 30 \mathrm{~min}$ for $60 \mathrm{~min}$ ). Average of 5 Vickers indentation kept under pressure for $15 \mathrm{~s}$.

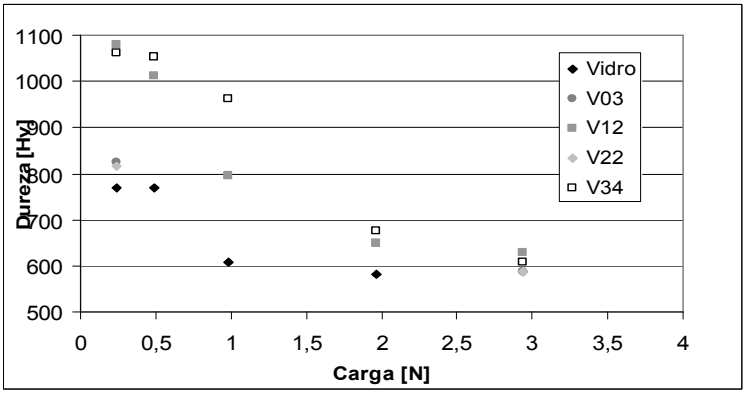

Figure 3. Hardness $\mathrm{TiO} 2$ film deposited on glass via magnetron sputtering (V03 for $10 \mathrm{~min}, 15 \mathrm{~min} V 12, \mathrm{~V} 22$ and V34 for $30 \mathrm{~min}$ for $60 \mathrm{~min}$ ). Average of 5 Vickers indentation kept under pressure for $15 \mathrm{~s}$.

Samples showed no indentation when the applied load was $0.0987 \mathrm{~N}$. Standard deviation is slightly larger to smaller loads. This is probably due to reduced accuracy in the measurement of the diagonals which are very small in lower forces. Another relevant fact is that the glass and ceramics are brittle materials. The indentation on glass at loads of $0.98 \mathrm{~N}, 1.9 \mathrm{~N}$ and $2.9 \mathrm{~N}$ have respectively 2,3 and 4 cracks. However, the film samples showed no cracking load of $0.98 \mathrm{~N}$. The ceramics showed no crack in any indentation. However, the deposited samples 30 and 60 min showed cracks when applied load of $2,9 \mathrm{~N}$.

The composite film substrate had always greater hardness than the substrate, although they showed curves follow the same pattern of substrate. For smaller loads there is a greater difference between the hardness achieved by the film and the substrate without film. For higher load values of the compound in Vicker are close to substrate. Reason for approximation substrate hardness compound is increase of sample indenter contact area. At higher loads, will deform the indenter further comprises a sample and increase contact area, and the load supported more by the volume of the substrate them by film.

Ceramic samples exhibit a distinct behavior of glass. For very small load $(0.24 \mathrm{~N})$ hardness is lower, increasing with the load $(0.49 \mathrm{~N})$ and then immediately the hardness decreases with increasing load, and as mentioned approaches the value of substrate hardness. Ceramic materials may have different behavior at low loads. For small forces on the sliding friction coefficient is high and decreases afterward due an elastoplastic behavior on the front of the indenter. Rea-son probable was at these small efforts indenter Vickers has imposed a film deformation that deformed plastically and thus had a lower hardness.

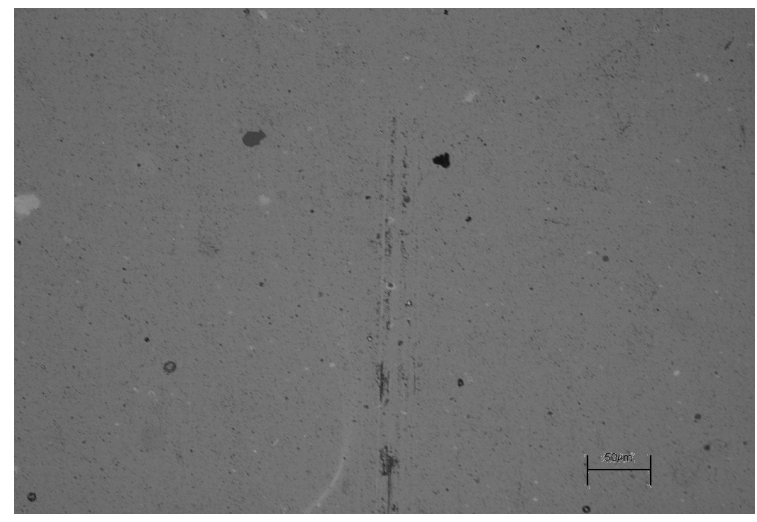

Figure 4. Scratch beginning at the sample deposited $10 \mathrm{~min}$. Sphere carbide sliding $2.5 \mathrm{~mm}$ to $1 \mathrm{~mm} / \mathrm{s}$. $200 \mathrm{X}$ microscope.

Figure 4 shows a scratch conducted with constant load of $0.5 \mathrm{~N}$. In this case the graph Fn and Ft to initially decrease, and then increase to approximately $0,5 \mathrm{~s}$. This same phenomenon was presented by all the scratch undertaken, including that with a rate of load increased with time. This variation of excessive force measured at the initial time of the scratch less than $0,5 \mathrm{~s}$, it is possible be a softening phenomenon, such as a seat on the tip of the ball or a break in deposited layer. Even graphic $\mathrm{Ft} / \mathrm{Fn}$ for this region has a lot of oscillation preventing a further interpretation of this. For better interpretation of results were taken from the graphs the initial and final moments of the scratchs. Optical microscope images analysis shows gradual entry of the 
sphere surface, see Figure 4. No scratch had a fracture or crack. Some are found within cracks parallel to scratch and, perhaps by passing a body of greater hardness, such as dirt, see Figure 5 and Figure 6 is showed scratch termination.

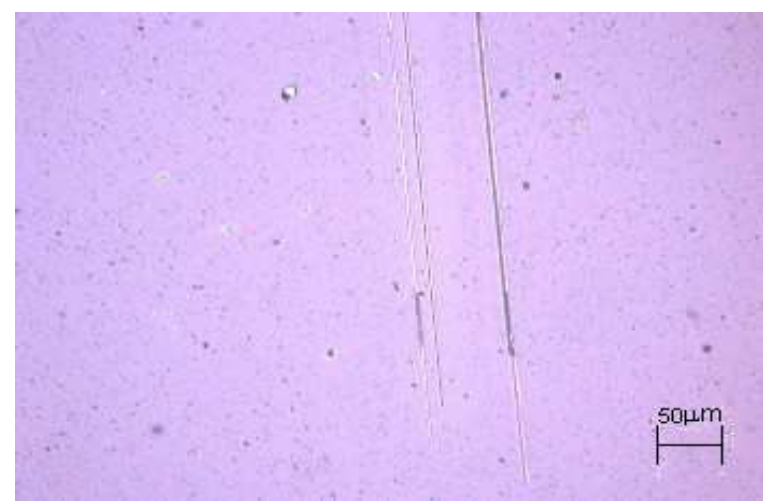

Figure 5. Scratch phase intermediate in sample deposited $15 \mathrm{~min}$. Sphere carbide sliding $2.5 \mathrm{~mm}$ to $1 \mathrm{~mm} / \mathrm{s}$. 200X microscope.

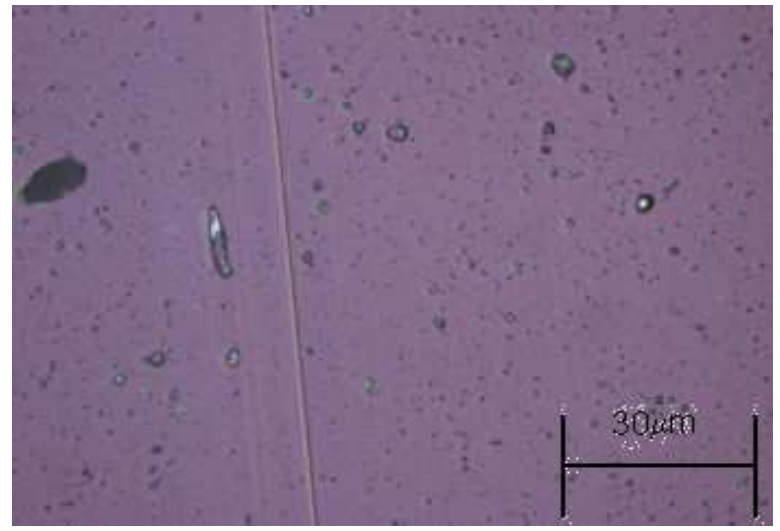

Figure 6. Scratch terminal in the sample deposited 15 min. Sphere carbide sliding $2.5 \mathrm{~mm}$ to $1 \mathrm{~mm} / \mathrm{s}$. $200 X$ microscope.

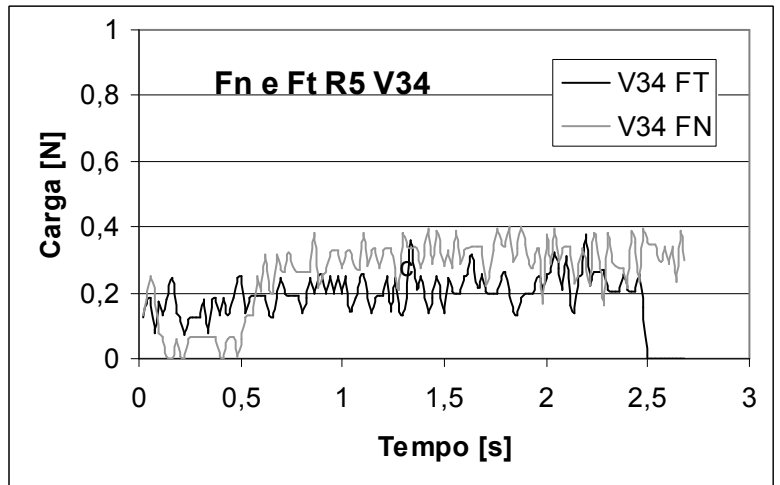

Figure 7. Graph of Fn and Ft is a scratch in sphere of $2.5 \mathrm{~mm}$ under load of $0.5 \mathrm{~N}$ and a speed-1 mm.s the TiO2 film deposited for $60 \mathrm{~min}$.

All films, in tests with increasing load, have downward trend in the apparent friction coefficient Ft / Fn. Table 1 are show the maximum values for the apparent friction coefficient.

Loads used in this geometry were not sufficient to determine the adhesion of the film substrate. Normal force was not reached a threshold required to rupture the layer of glass or chipping. However, Figure 9 shows the result scratch of unknown conditions which appear in more severe fractures indicating critical load is exceeded. This occurred with the scratch of a sample with 30 minutes of deposition under conditions of extreme test. This was load lost control test and resultant scratch reached the critical condition. Thus, under more severe conditions as in higher loads or smaller radius indenter the critical condition is reached.

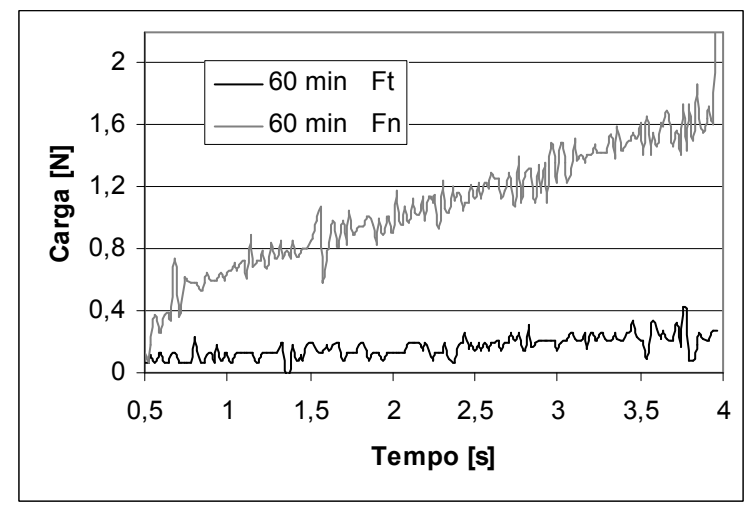

Figure 8. Graph of Fn and Ft is a scratch in sphere of $2.5 \mathrm{~mm}$ under an initial load of $0.5 \mathrm{~N}$ with an increment of 1 and $0.5 \mathrm{~N} . \mathrm{s}$-speed $1 \mathrm{~mm} . \mathrm{s}-1$ in the deposited film for $60 \mathrm{~min}$.

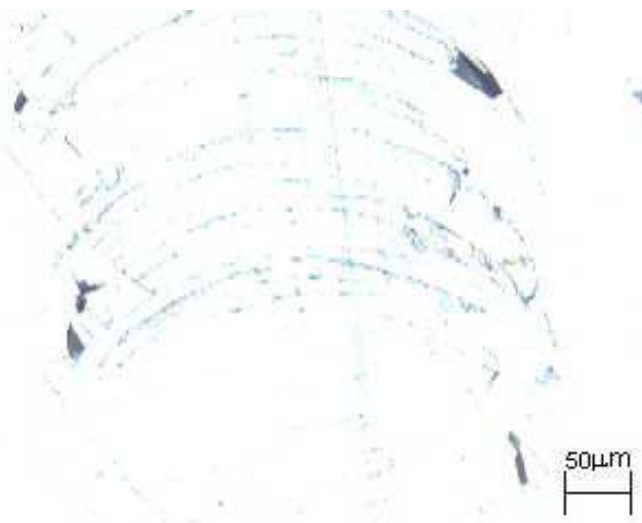

Figure 9. Sample deposition in $30 \mathrm{~min}$. Test conditions were not controlled, was lost control of the applied load.

Table 1. Approximate values of the apparent friction Ft / Fn. Sphere carbide sliding $2.5 \mathrm{~mm}$ to $1 \mathrm{~mm} / \mathrm{s}$ into the sample coated with the films deposited for 15,30 and $60 \mathrm{~min}$.

\begin{tabular}{cc}
\hline Film & aparent friction Ft/Fn \\
\hline 15 min & $<0,2$ \\
$30 \mathrm{~min}$ & $<0,2$ \\
$60 \mathrm{~min}$ & $<0,4$ \\
\hline
\end{tabular}

\section{Conclusion}

The films are composed of Titania in the rutile and anatase form, stages of similar hardness, can be considered that the composition and morphology of the film are not variables significant for this analysis. In this case the film 
thickness is the variable to be studied.

The Titania film deposited by magnetron sputtering has good adhesion to the substrate, since there was no cracking or chipping of the film in used testes conditions.

Was not reached critical force for breaking or chipping of the layer of glass, so it will need to conduct further experi-ments on a larger load or pyramidal indenter to determine the critical condition.

\section{References}

[1] G. R. Jacobs et al. A certified reference material for the scratch test original research. Surface and Coatings Technology, v. 174-175, September-October (2003), p. 1008-1013

[2] H. Ishimura, A. Rodrigo. Surface coating Technology. v. 126, I. 2-3, 24 April (2000), p. 152-158
[3] H. Ichimura, Y. Ishii. Effects of indenter radius on the critical load in scratch testing Original Research Article. Surface and Coatings Technology, v. 165, I.1, 3 February (2003), p. 1-.

[4] V. Fervel, B. Normand, C. Coddet, Tribological behavior of plasma sprayed $\mathrm{Al} 2 \mathrm{O} 3$-based cermet coatings. Wear, v. 230, (1999), p. 70-77.

[5] J. F. Li, J. Q. Huang, A. Y. F. Zhang, C. X. Ding, P. Y. Zhang. Friction and wear behavior of plasma-sprayed $\mathrm{Cr} 3 \mathrm{C} 2-\mathrm{NiCr}$ against $\mathrm{TiO} 2$ coating under water- and ethanol-lubricated sliding. Wear, 214 (1998) 202-206.

[6] W. Zhang, W. Liu, C. Wang. Tribological behavior of sol-gel TiO2 films on glass. Wear 253 (2002) 377-384.

[7] P. J. Kelly, C. F. Beevers, P. S. Henderson,R.D. Arnell, J. W. Bradley, H. Bacher. A comparison of the properties of titanium-based films produced by pulsed and continuous DC magnetron Sputtering. Surface and coatings technology 174-175(2003) 795-800. 